\title{
Associations between LDL/HDL-cholesterol ratio and thoracic and abdominal aortic atherosclerosis assessed by MRI
}

\author{
Yukihiko Momiyama ${ }^{1 *}$, Reiko Ohmori ${ }^{2}$, Ryuichi Kato ${ }^{2}$, Hiroaki Taniguchi $^{2}$, Masayoshi Nagata ${ }^{3}$, Fumitaka Ohsuzu ${ }^{2}$ \\ From 15th Annual SCMR Scientific Sessions \\ Orlando, FL, USA. 2-5 February 2012
}

\section{Background}

Recently, the LDL/HDL-cholesterol ratio has become recognized as a stronger risk predictor of cardiovascular diseases than each lipid parameter. However, the association between LDL/HDL-cholesterol ratio and aortic atherosclerosis has not been elucidated yet. Using MRI, we investigated the associations between thoracic and abdominal aortic atherosclerosis and LDL/HDL-cholesterol ratio as well as LDL- and HDL-cholesterol levels.

\section{Methods}

Aortic MRI was performed on Signa 1.5T Cvi using a phased-array body coil in 159 patients at high-risk for CAD. However, since statins affect LDL- and HDL-cholesterol levels, 64 patients who were taking statin were excluded from this study. Transverse PDW and T2W images of thoracic descending and abdominal aortas were obtained using an ECG-gated, double-inversionrecovery FSE sequence: $\mathrm{TR}=2 \mathrm{RR}$ intervals, $\mathrm{TE}=10 \mathrm{~ms}$ (PDW) and $60 \mathrm{~ms}$ (T2W), 20-cm FOV, 4-mm slice thickness, 8-mm inter-slice gap, 256x256 acquisition matrix, and 32 echo-train. For each patient, 9 slices of thoracic aorta and 9 slices of abdominal aorta were obtained at $12-\mathrm{mm}$ intervals, which each covered about $10-\mathrm{cm}$ portion of thoracic aorta below the arch and $10-\mathrm{cm}$ portion of abdominal aorta above the bifurcation of iliac artery. Plaque extent in each slice was scored 0 to 4 points by the percentage of luminal surface involved by plaque. The severity of aortic atherosclerosis was represented as sum of scores (plaque score).

'Department of Cardiology, National Hospital Organization Tokyo Medical Center, Tokyo, Japan

Full list of author information is available at the end of the article

\section{Results}

Among the 95 study patients without statin (age $63 \pm 9$ years), thoracic and abdominal aortic plaques were found in $60(63 \%)$ and $84(88 \%)$ patients, respectively. The severities of both thoracic and abdominal aortic atherosclerosis correlated with age and blood pressures. Regarding lipid parameters, the severity of thoracic aortic atherosclerosis correlated with LDL-cholesterol $(\mathrm{r}=0.30)$ and HDL-cholesterol $(\mathrm{r}=-0.26)$ levels $(\mathrm{P}<0.01)$ and much better with LDL/HDL-cholesterol ratio $(\mathrm{r}=0.36, \mathrm{P}<0.001)$. However, the severity of abdominal aortic atherosclerosis correlated with only HDL-cholesterol level $(r=-0.29, \mathrm{P}<0.005)$ but not with $\mathrm{LDL}$-cholesterol or LDL/HDL-cholesterol ratio $(\mathrm{P}=\mathrm{NS})$. In multiple linear regression analysis, age and LDL/HDL-cholesterol ratio were the independent factors associated with thoracic aortic atherosclerosis, whereas age and HDL-cholesterol level as well as HbA1c and smoking were the factors associated with abdominal aortic atherosclerosis.

\section{Conclusions}

Among lipid parameters, the LDL/HDL-cholesterol ratio was found to be a stronger factor associated with thoracic aortic atherosclerosis than either LDL-cholesterol or HDL-cholesterol levels, whereas abdominal aortic atherosclerosis was associated with only HDL-cholesterol levels. Our results suggest that thoracic and abdominal aortas may have different susceptibilities to atherosclerotic risk factors. MRI is a very useful tool for non-invasively evaluating atherosclerosis in both thoracic and abdominal aortas.

\section{Funding}

Our study had no funding. 


\section{Author details}

'Department of Cardiology, National Hospital Organization Tokyo Medical

Center, Tokyo, Japan. ${ }^{2}$ National Defense Medical College, Tokorozawa, Japan.

${ }^{3}$ Iruma Heart Hospital, Saitama, Japan.

Published: 1 February 2012

doi:10.1186/1532-429X-14-S1-P72

Cite this article as: Momiyama et al:: Associations between LDL/HDL-

cholesterol ratio and thoracic and abdominal aortic atherosclerosis assessed by MRI. Journal of Cardiovascular Magnetic Resonance 201214

(Suppl 1):P72.

Submit your next manuscript to BioMed Central and take full advantage of:

- Convenient online submission

- Thorough peer review

- No space constraints or color figure charges

- Immediate publication on acceptance

- Inclusion in PubMed, CAS, Scopus and Google Scholar

- Research which is freely available for redistribution

Submit your manuscript at www.biomedcentral.com/submit 